\title{
The Influence of Water on the Temperature of Amphibole Stability in Melts
}

\author{
A. P. Maksimov \\ Institute of Volcanology and Seismology, Far East Division, Russian Academy of Sciences, \\ Petropavlovsk-Kamchatskii, 683006 Russia
}

Received December 19, 2007

\begin{abstract}
The influence of water concentration on the crystallization temperature of amphibole in a melt was analyzed theoretically using the model of an ideal melt. A general-type equation has been derived that can explain the presence of the isobaric temperature maximum at the amphibole stability curve by invoking the twofold influence of water on the equilibrium between amphibole and the melt: in accordance with the crystallization reaction, water increases the stability of amphibole, but at the same time it decreases the mole fractions of the other melt components that are taking part in the amphibole crystallization reaction, thereby decreasing the stability of amphibole. The pargasite-water-carbon dioxide system was used as an example to show that the model is a good fit to the experimental data. The data were used to obtain the coefficients in the equations that relate the constants of pargasite-melt and tremolite-melt equilibria to temperature and pressure.
\end{abstract}

DOI: $10.1134 / \mathrm{S} 0742046309010035$

\section{INTRODUCTION}

Amphibole is the most common phenocryst mineral found in volcanic rocks. It is given an important role in several models developed to explain the origin of andesites and more acidic representatives of the islandarc volcanic calc-alkaline series [2]. Special interest is given to amphibole as a critical indicator of physicochemical conditions for melt crystallization, such as total pressure, water pressure, and the temperature and concentration of water. In this connection the petrologists need to understand how the thermodynamic parameters affect the stability of amphibole and to derive quantitative characteristics of the appropriate relations. However, because of the complex composition and structure of amphiboles, the problems of an adequate thermodynamic description of their behavior in melts and of applying the results to naturally occurring magmas arise. Therefore, at the present one has to make a number of assumptions when modeling equilibria involving amphiboles.

A previous study of mine has shown that the behavior of melting curves for anhydrous silicates in water melts can be described by the ideal model of water particle dilution in a melt $[3,21]$. That feasibility of this approach has been demonstrated in application to the crystallization of the water phase for amphibole [22].

Ghiorso [12] analyzed the general principles of the influence of water on the stability of water phases in melts using a different approach. It was shown that the ideal model can describe the leading effects in the behavior of water phases, showing that it is the concentrations of components that control the process, while the activity coefficients can be neglected in the first approximation. The results of my study were derived independently and are consistent with the above reference. However, these results have not been published in full detail. They differ from [12] in their approach and in their application to experimental data. It is therefore reasonable to set them forth in greater detail.

\section{THE BEHAVIOR OF AMPHIBOLE STABILITY CURVES}

The behavior of amphibole in melts is, similarly to other water phases, different from that of anhydrous silicates. The presence of amphibole in rocks is frequently thought to be related to the hydrous character of the associated magmas, while the absence of amphibole is ascribed to low concentrations of water. This is not true in the general case, since the stability of amphibole depends on several other parameters, apart from the presence of sufficient amounts of water in the magmatic system [2, 4-6, 11, 14, 25]. The foremost among these parameters are the total pressure, the composition of the fluid phase, and the temperature. Also of great importance are the melt composition and the reduction-oxidation processes in the magma. The total pressure at which phenocryst crystallization occurs is the controlling factor for amphibole stability in the more mature members of island-arc series (andesite-rhyolite), because sufficient amounts of water are accumulated in such magmas during their evolution. In other words, the appearance of amphibole-bearing rocks on a volcano primarily depends on the depth to the associated magma chamber. To bring this out with more clarity we will consider the influence of water pressure, temperature and regime on amphibole stability. 

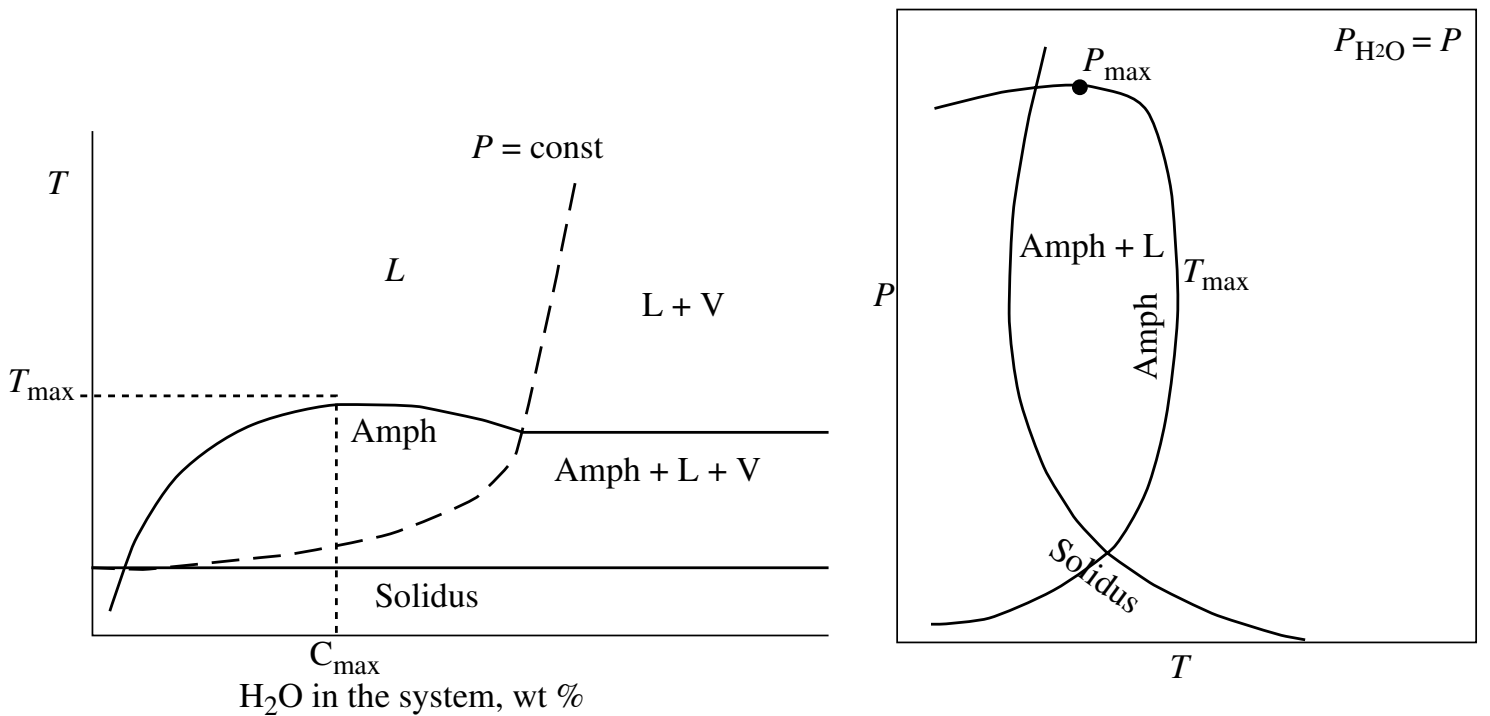

Fig. 1. Diagrammatic curves of amphibole stability (Amph): (a) amphibole stability curve in a melt at a constant total pressure $(P)$, (b) $P-T$ curve of Amph stability in water-saturated conditions $\left(P_{\mathrm{H}_{2} \mathrm{O}}=P\right)$. $L$ denotes melt, $V$ vapor, $P_{\mathrm{H}_{2} \mathrm{O}}$ water pressure, $T_{\text {max }}$ the maximum temperature of amphibole stability in melt under isobaric $(a)$ and water-saturated $(b)$ conditions, $C_{\max }$ the water concentration at the point where the isobaric maximum of amphibole stability is attained, $P_{\min }$ and $P_{\max }$ are the minimum and the maximum pressures of amphibole stability in the melt.

The general view of the amphibole stability region (Amph) is shown in Figs. $1 \mathrm{a}$ and $1 \mathrm{~b}$ in the $P-T$ and $T-$ $\mathrm{H}_{2} \mathrm{O}$ coordinates. In contrast to anhydrous phases, which have a temperature minimum at the $P-T$ melting curves under $\mathrm{H}_{2} \mathrm{O}$-undersaturated and water-saturated conditions, the curve of amphibole stability in watersaturated conditions has a temperature and a baric maximum (Fig. 1a). To take an example, amphibole in andesitic magma is unstable at temperatures above 5 [2, $11,14,25,26]$ and pressures in excess of $\sim 18-20$ kbars [5]. As well, there is the lowest limiting pressure of amphibole crystallization in the melt, which is determined by the intersection of the amphibole stability curve and the solidus curve. For andesitic and more acidic melts in water-saturated conditions (when $\left.P_{\mathrm{H}_{2} \mathrm{O}}=P_{\text {total }}\right)$ that pressure value is in the range of 0.5 1.5 kbars according to different researchers, that is, at

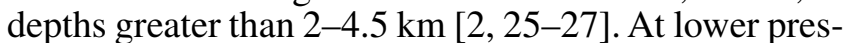
sures, amphibole is unstable in magmas, no matter what the amount of water is in the system, and can only be of secondary, postmagmatic, or metamorphic origin. Hornblende crystallization in naturally occurring magmas takes place at temperatures much greater than the solidus, because the fraction of phenocrysts in amphibole-bearing volcanic rocks is not generally above 30$40 \%$. Amphibole crystallization in such magmas can occur at higher pressures than what can be deduced from the intersection of the amphibole stability curve and the solidus. The lowest pressure at which amphibole-bearing rocks can crystallize increases to reach $2-$ $3 \mathrm{kbars}$ (corresponding to depths of $\sim 6-9 \mathrm{~km}$ ). If the magma also contains $\mathrm{CO}_{2}$, in addition to water, then the solidus line will lie higher in temperature than is the case for purely hydrous (water-saturated) conditions. Accordingly, the pressure at which the solidus intersects the amphibole stability curve will be higher.

At a constant pressure and an increasing water concentration in a melt, the Amph stability temperature dramatically rises at first, reaches its maximum, and afterwards may decrease, in contrast to the continuously decreasing temperature of the anhydrous phase liquidus [11, 14] (Fig. 1a). This phenomenon has been demonstrated in detail by experimenting with a system consisting of pargasite-water- $\mathrm{CO}_{2}$ [18]. There are several previous explanations of this effect. One consists in a possible change of the reaction that controls amphibole stability, from hydration to melting, as the activity of water is increasing, because water exerts opposite effects on these reactions [11]. According to another researcher, the water content in amphibole at the maximum point corresponds to water solubility in the melt under given $P-T$ conditions [18].

\section{THE GENERAL EQUATION: AN ANALYSIS}

To describe the behavior of the water phase in a melt we used an approach treating the melt as an ideal solution; this approach was used previously to describe the stability of anhydrous phases in water-saturated melts. The general form of the equation for minal crystallization ( $M$ contained in amphibole Amph) can be written as

$$
a A^{L}+b B^{L}+\ldots+k K^{L}+w W^{L}=M^{\mathrm{Amph}},
$$


where $A^{L}, B^{L}, \ldots, K^{L}$ are oxides in the melt $(L)$ on a onecation basis; $W$ denotes water; $a, b, \ldots, k$, are stoichiometric coefficients; and $w$ is the number of particles which result from water dilution (between 1 and 2). The activity for component $i$ in an ideal solution (melt) is equal to the mole fraction $\left(X_{i}\right)$. In this case the equilibrium constant for reaction (1) is expressed by

$$
\ln K=\ln \frac{X_{M}^{\mathrm{Amph}}}{\left(X_{A}\right)^{a}\left(X_{B}\right)^{b} \cdot \ldots \cdot\left(X_{K}\right)^{k}\left(X_{W}\right)^{w}} .
$$

According to the generally accepted view, the equilibrium constant as a function of temperature $\left(T,{ }^{\circ} \mathrm{K}\right)$ and pressure ( $P$ bars) for condensed phases (crystals and melt) can be represented in the form

$$
\ln K=\frac{A}{T}+B+C \frac{P-1}{T},
$$

where $A, B$, and $C$ are constants ${ }^{1}$. The equation can be simplified when it is to be used to analyze amphibole stability at a constant pressure:

$$
\ln K=\frac{A+C(P-1)}{T}+B=\frac{A_{P}}{T}+B,
$$

where $A_{P}=A+C(P-1)$.

Using Eqs. (2) and (4) for some melt as a starting point, one can analyze the effect of increasing water concentration on the amphibole stability temperature. We assume a melt containing a fixed number of water particles $h_{\mathrm{o}}$ as the standard. The mole fraction of component $i$ in a water melt $X_{i}$ is expressed as

$$
X_{i}=n_{i} /\left(n_{s}+n_{w}\right),
$$

where $n_{i}$ is the number of moles (cations) of component $i$ in the melt, $n_{s}$ is the total number of silicate cations in the melt, and $n_{w}$ the number of water particles in the melt. If $h$ water particles have been added to the standard melt, then

$$
\begin{aligned}
X_{i}=n_{i} /\left(n_{s}+h_{o}+h\right) & =n_{i} /\left(n_{0}+h\right), \\
X_{w}=\left(h_{0}+h\right) /\left(n_{s}+h_{0}+h\right) & =\left(h_{0}+h\right) /\left(n_{0}+h\right),
\end{aligned}
$$

where $n_{0}=n_{s}+h_{0}$.

We will denote the equilibrium constant of reaction (1) for the standard melt as $K_{0}$. To simplify subsequent analysis we will assume that the composition of amphibole and the silicate part of the melt are not affected by varying water concentration in the melt. Eqs. (2) and $(6,7)$ will then give the equilibrium constant for a melt with a different water concentration:

$$
\ln K=\ln K_{0}+m \ln \left(1+h / n_{0}\right)-w \ln \left(1+h / h_{0}\right) .
$$

\footnotetext{
${ }^{1}$ This relation implies that, first, the heat capacity of reaction (1) is $\Delta C_{p}$, so that the enthalpy $\left(\Delta H_{0}\right)$ and entropy $\left(\Delta S_{0}\right)$ of the reaction do not depend on the temperature and, secondly, the volumetric effect of the reaction $\Delta V_{o}$ is independent of the temperature and pressure, i.e., $A=-\Delta H_{0} / R, B=\Delta S_{o} / R, C=-\Delta V_{o} / R$.
}

Substitution of this expression in (4) gives, after some manipulation:

$$
T=\frac{A_{P}}{\ln K_{0}+m \ln \left(1+h / n_{0}\right)-w \ln \left(1+h / h_{0}\right)-B},
$$

where $m=a+b+\ldots+k+w$.

The resulting equation predicts the presence of a maximum and can be used to estimate its location. Denote

$$
D=m \ln \left(1+h / n_{0}\right)-w \ln \left(1+h / h_{0}\right) .
$$

Differentiation of (9) with respect to $h$ at constant pressure gives

$$
\left(\frac{\partial T}{\partial h}\right)_{P}=-\frac{A_{P}}{\left(\ln K_{0}-B+D\right)^{2}} \frac{d D}{d h}
$$

The above derivative must vanish at the temperature maximum point in the isobaric curve of amphibole stability. Hence, comparing (9) and (10), one gets

$$
\frac{d D}{d h}=\frac{m}{n_{0}+h}-\frac{w}{h_{0}+h}=\frac{m}{n_{s}+h^{\max }}-\frac{w}{h^{\max }}=0,
$$

where $h^{\max }=h_{0}+h$ is the number of water particles at the maximum point:

$$
h^{\max }=\frac{w n_{s}}{m-w} .
$$

Relation (12) is the condition for a temperature extremum in the isobaric curve of amphibole melting. Since the expression $A_{P}=A+C(P-1)$ in (10) is always positive, it follows that $\left(\frac{\partial T}{\partial h}\right)_{P}>0$ for $h<h^{\max }$ and $\left(\frac{\partial T}{\partial h}\right)_{P}<0$ for $h>h^{\max }$. Hence the amphibole stability curve passes through the temperature minimum at the point $h^{\max }$ at constant pressure in the $T$ vs $\mathrm{H}_{2} \mathrm{O}$ plot. It can be shown that the water concentration $C_{w}$ at the maximum point $C^{\max }$ is independent of the form the water is found in the melt. For example, if the water is in molecular form in (1), i.e., $w=1$, then $100 \mathrm{~g}$ of the melt contains $h=C_{w} / 18$ water particles and

$$
\begin{aligned}
h^{\max }=\frac{w n_{s}}{m-w} & =\frac{n_{s}}{m-1}=\frac{n_{s}}{a+b+\ldots+k}, \\
C^{\max } & =\frac{18 n_{s}}{a+b+\ldots+k},
\end{aligned}
$$

where $a, b, \ldots, k$ are the stoichiometric coefficients in (1). If the melt contains water in hydroxylic form, i.e., 
$w=2$ and $h=C_{w} / 9$, then we arrive at the same expression for $C^{\max }$ :

$$
\begin{gathered}
h^{\max }=\frac{2 n_{s}}{m-2}=\frac{2 n_{s}}{a+b+\ldots+k}, \\
C^{\max }=\frac{18 n_{s}}{a+b+\ldots+k} .
\end{gathered}
$$

Relation (13) can be used to obtain an approximate estimate of water concentration at the point $T^{\max }$. For example, this will be $\sim 2.2 \mathrm{wt} \%$ for a tremolite melt $\left(\mathrm{Ca}_{2} \mathrm{Mg}_{5} \mathrm{Si}_{8} \mathrm{O}_{22}(\mathrm{OH})_{2}\right)$ for melting in accordance with (1).

The presence of an isobaric temperature maximum of amphibole stability can be explained by water acting in two directions on the amphibole equilibrium: on the one hand, water enhances amphibole stability in accordance with the crystallization reaction, while on the other, it dilutes the melt, thereby decreasing the mole fractions of the other components that are involved in the amphibole melting-crystallization reaction and thus decreases amphibole stability.

\section{QUANTITATIVE ESTIMATION OF THE EQUATION: \\ THE PARGASITE- $\mathrm{H}_{2} \mathrm{O}-\mathrm{CO}_{2}$ SYSTEM}

We estimated quantitatively whether the present approach is viable by using the experimental results for the system consisting of pargasite- $\mathrm{H}_{2} \mathrm{O}-\mathrm{CO}_{2}$ reported in [18]. The data have a definite advantage in that they do not require calculating the activity of solid reaction components, because the reaction involves pure mineral phases only, and there is no need to incorporate oxygen fugacity, since the system does not contain iron.

Neglecting the solubility of $\mathrm{Al}_{2} \mathrm{O}_{3}$ in diopside (Di), the reaction of incongruent pargasite (Parg) melting can be represented as [18]

$$
\text { Parg }=1.5 \mathrm{Di}+\mathrm{Fo}+0.5 \mathrm{Sp}+\mathrm{L}+\mathrm{H}_{2} \mathrm{O} \text {, }
$$

where Fo stands for forsterite, Sp for spinel, and L for melt. When the dissolved water is disregarded, the melt composition corresponds to the mixture $\mathrm{Ne}$ (nepheline) $+0.5 \mathrm{An}$ (anorthite) or $\mathrm{NaCa}_{0.5} \mathrm{Al}_{2} \mathrm{Si}_{2} \mathrm{O}_{8}$. Hence, recalling that the activity of a pure mineral phase is 1 and expressing the melt components on a one-cation basis, the reaction constant for (14) can be written as

$$
\begin{gathered}
\ln K=\ln X_{\mathrm{Na}}+0.5 \ln X_{\mathrm{Ca}} \\
+2 \ln X_{\mathrm{Al}}+2 \ln X_{\mathrm{Si}}+2 \ln X_{\mathrm{H}},
\end{gathered}
$$

where $X_{i}$ are the fractions of cations in the melt. Because for the melt under consideration one has $X_{\mathrm{Ca}}=2 X_{\mathrm{Na}}=4 X_{\mathrm{Si}}=4 X_{\mathrm{Al}}$, the result will be

$$
\begin{gathered}
\ln K=-5.5 \ln [11+62.41 / Z] \\
-2 \ln [62.41+11 Z]+2 \ln 62.41,
\end{gathered}
$$

where $Z=(100-C) / C$, with $C$ being the water concentration in the melt, wt $\%$. The equilibrium constant as a function of temperature and pressure was calculated taking changes in the water mole volume into account in the melt $\left(V_{w}\right)$ from the equation

$$
\ln K=\frac{A}{T}+B+C \frac{P-1}{T}-\frac{1}{R T} \int_{P_{0}}^{P} V_{w} d P .
$$

The coefficients in the equilibrium constant as a function of $T$ and $P$ were found using the experimental data at 5 and 8 kbars from [18]. The water concentration in the melt was calculated using the model of [8]. The data for the albite-water system [9] were used as the mole fractions of water in the melt. The coefficients were calculated in two steps. At first, the method of least squares was applied to (4) at $5 \mathrm{kbars}$ to find $A_{P}$ and $B$. The next step was to make use of these coefficients and the experimental data for $8 \mathrm{kbars}$ to find $A$ and $C$ in a similar manner from Eq. (17) at $P_{0}=5$ kbars.

The resulting coefficients in (17) were used to find the positions of pargasite melting curves in the $P-T$ coordinates for different mole fractions of water in the fluid $\mathrm{XH}_{2} \mathrm{O}$ (Fig. 2a) and in the $T-\mathrm{X}_{\mathrm{H}_{2} \mathrm{O}}$ coordinates for different pressures (Fig. 3a). The results are shown in the plots along with the experimental data taken from [18] (Figs. 2b, 3b). The plots provide a faithful imitation of the experimental curves and are quite consistent with these as to absolute position. We note that the incorporation of varying water mole volume in the melt did not significantly alter the results.

\section{EQUATIONS FOR TREMOLITE AND PARGASITE CRYSTALLIZATION BASED ON EXPERIMENTAL DATA}

The consistency found to exist between calculated and experimental values confirms that the present approach is valid and can be used to derive equations describing the behavior of actual amphiboles in naturally occurring melts. As a first step, we used the above approach to derive equations for tremolite and pargasite crystallization using experimental information from the INFOREX data base [1]. The first calculation version used the hydroxylic form of water dissolved in the melt to analyze tremolite-melt equilibria:

$$
\begin{gathered}
2 \mathrm{CaO}^{\mathrm{L}}+5 \mathrm{MgO}^{\mathrm{L}}+8 \mathrm{SiO}_{2}^{\mathrm{L}}+2 \mathrm{HO}_{0.5}^{\mathrm{L}} \\
=\mathrm{Ca}_{2} \mathrm{Mg}_{5} \mathrm{Si}_{8} \mathrm{O}_{22}(\mathrm{OH})_{2}^{\mathrm{Amph}}
\end{gathered}
$$

and the pargasite-melt equilibria:

$$
\begin{gathered}
\mathrm{NaO}_{0.5}^{\mathrm{L}}+2 \mathrm{CaO}^{\mathrm{L}}+4 \mathrm{MgO}^{\mathrm{L}} \\
+3 \mathrm{AlO}_{1.5}^{\mathrm{L}}+6 \mathrm{SiO}_{2}^{\mathrm{L}}+2 \mathrm{HO}_{0.5}^{\mathrm{L}} \\
=\mathrm{NaCa}_{2} \mathrm{Mg}_{4} \mathrm{Al}\left[\mathrm{Al}_{2} \mathrm{Si}_{6}\right] \mathrm{O}_{22}(\mathrm{OH})_{2}^{\mathrm{Amph}} .
\end{gathered}
$$

The chief difficulty in this method of analyzing equilibria with amphibole is that it is difficult to estimate the mole fractions and activities of its minals. 


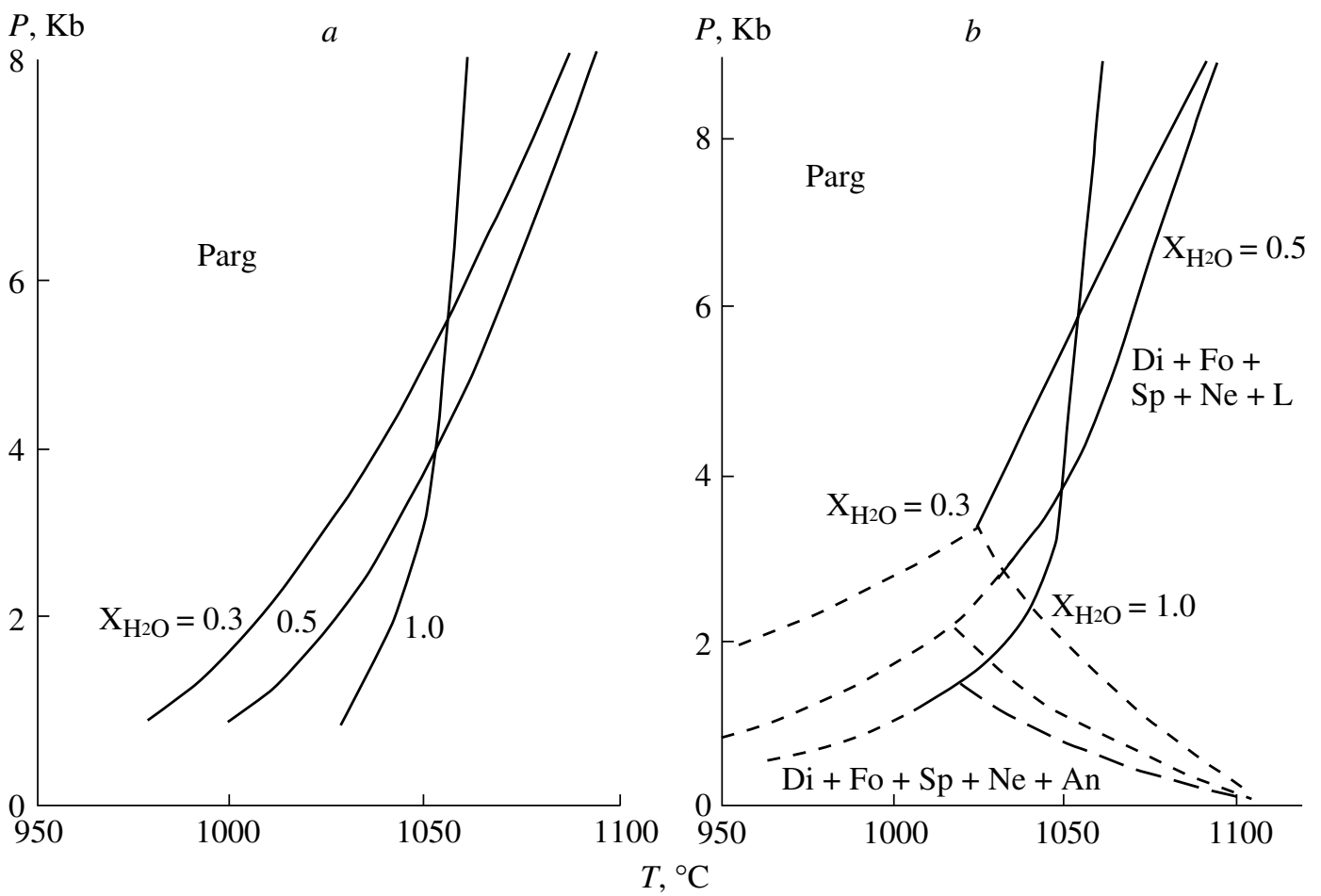

Fig. 2. $P-T$ curves of pargasite stability for different mole fractions of water in the fluid $\left(X_{\mathrm{H}_{2} \mathrm{O}}\right):(a)$ theory, $(b)$ experimental data [18].

Because of this ambiguity, we had to make several assumptions and suppose that the consistent calculation scheme used to derive the equation and its subsequent use will smooth out these errors. The activities of tremolite and pargasite in amphibole were assumed to be equal to their respective mole fractions. The structural formula of amphibole was calculated for 23 oxygens. The calculation of the $\mathrm{Fe}^{3+}$ fraction and the distribution of cations for positions in the amphibole formula was carried out using the procedure presented in [10, 17]. The distribution of $\mathrm{Fe}-\mathrm{Mg}$ at positions was assumed following [23]. The temperature required to calculate the distribution was assumed to be equal to the experimental one. The mole fractions of tremolite and pargasite in amphibole were expressed as

$$
\begin{gathered}
X_{\text {trent }}=X_{V}^{A} \cdot\left(X_{\mathrm{Mg}}^{M 4}\right)^{2} \cdot\left(X_{\mathrm{Mg}}^{M 2}\right)^{5} \cdot\left(X_{\mathrm{Si}}^{T 1}\right)^{4} \cdot\left(X_{\mathrm{OH}}\right)^{2}, \\
X_{\mathrm{parg}}=X_{\mathrm{Na}}^{A} \cdot\left(X_{\mathrm{Ca}}^{M 4}\right)^{2} \cdot\left(X_{\mathrm{Mg}}^{M 13}\right)^{3} \cdot \\
\cdot X_{\mathrm{Mg}}^{M 2} \cdot X_{\mathrm{Al}}^{M 2} \cdot\left(X_{\mathrm{Al}}^{T 1}\right)^{2} \cdot\left(X_{\mathrm{Si}}^{T 1}\right)^{2} \cdot\left(X_{\mathrm{OH}}\right)^{2} .
\end{gathered}
$$

where $X_{I}^{P}$ are fractions of cations $(I)$ at respective positions $(P)$ in amphibole structure, $V$ are vacancies. We have for the equilibrium constants in (16) and (17):

$$
\begin{gathered}
\ln K_{\text {trent }}=\ln X_{\text {trent }}-2 \ln X_{\mathrm{Ca}}^{\mathrm{L}} \\
-5 \ln X_{\mathrm{Mg}}^{\mathrm{L}}-8 \ln X_{\mathrm{Si}}^{\mathrm{L}}-2 X_{\mathrm{H}}^{\mathrm{L}}, \\
\ln K_{\mathrm{parg}}=\ln X_{\text {parg }}-\ln X_{\mathrm{Na}}^{\mathrm{L}}-2 \ln X_{\mathrm{Ca}}^{\mathrm{L}} \\
-4 \ln X_{\mathrm{Mg}}^{\mathrm{L}}-3 \ln X_{\mathrm{Al}}^{\mathrm{L}}-6 \ln X_{\mathrm{Si}}^{\mathrm{L}}-2 \ln X_{H}^{\mathrm{L}} .
\end{gathered}
$$

We used to the INFOREX software package to select amphibole-melt composition pairs based on experiments at pressures below $10 \mathrm{kbars}$, for which the mole fractions of water in the fluid phase were known. From this set we eliminated the experiments with low concentrations of $\mathrm{MgO}$ in the melt $(<0.5 \mathrm{wt} \%)$ in view of the large error caused by the parameter in these cases. A total of 44 composition pairs were selected from $[7,13,15,16,19,20,24,28]$. From these we calculated logarithms of the constants in the crystallization equations for tremolite and pargasite using Eqs. (22) and (23). Since the use of Eq. (17) did not greatly improve the results, but complicated the calculations unnecessarily, it was decided to use Eq. (3), for which the method of least squares yielded the constants $A, B$, and $C$ :

\section{JOURNAL OF VOLCANOLOGY AND SEISMOLOGY Vol. 3 No. 12009}




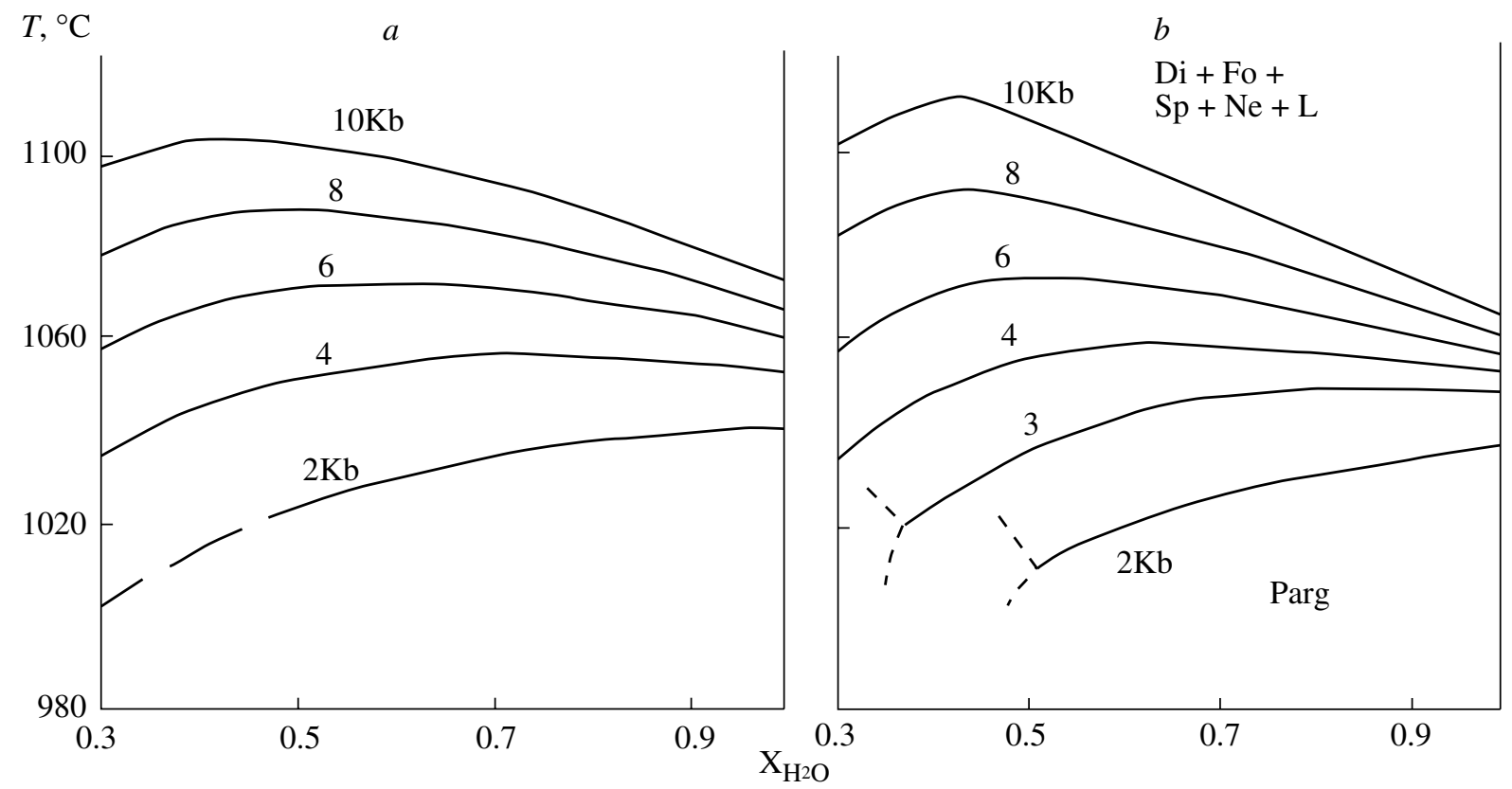

Fig. 3. Upper limiting temperature of pargasite stability versus the mole fraction of water in the fluid at different pressures: (a) theory, $(b)$ experimental data [18].

The mean deviations of calculated temperature from the experimental values are about $35^{\circ}$ for both equilibria. In view of the assumptions made and the errors in experimental data, this result can be considered to be acceptable for crude estimation. However, some of the individual discrepancies between calculated and experimental temperatures are 2-2.5 times this value, which seems to indicate that the approach used here is rather crude. The differences between the temperatures calculated from the data for tremolite and pargasite do not commonly exceed $25^{\circ} \mathrm{C}$, but occasionally reach $45^{\circ} \mathrm{C}$.

Later, such calculations were also carried out for other versions of the equilibrium equations. Calculations based on equations that are analogous to (18) and (19), except for the molecular form of water in the melt, yielded practically identical results from the standpoint of the calculated temperatures and agreement with the experimental values. The results also were not improved by varying the assumed number of silicate particles in the melt in accordance with the equation

$$
\begin{gathered}
2 \mathrm{CaO}^{\mathrm{L}}+5 \mathrm{MgO}^{\mathrm{L}}+\mathrm{Si}_{8} \mathrm{O}_{16}{ }^{\mathrm{L}}+2 \mathrm{HO}_{0.5}{ }^{\mathrm{L}} \\
=\mathrm{Ca}_{2} \mathrm{Mg}_{5} \mathrm{Si}_{8} \mathrm{O}_{22}(\mathrm{OH})_{2}{ }^{\mathrm{Amph}} .
\end{gathered}
$$

In this last equation, the number of silicate particles in the melt is equal to 8, while the figure is 15 in Eq. (18). In accordance with Eq. (9), the effect of water on the equilibria (18) and (24) must differ significantly because of the different effects due to the decreasing mole fractions of the melt components on water dilution. This result calls for further analysis.

\section{CONCLUSIONS}

The results of the present analysis show that the behavior of amphibole in melts can be explained within the framework of the ideal model for dissolution of water. The effects due to the activity coefficients of melt components can be neglected in the first approximation. The insufficient accuracy of the results for experimental compositions may point both to the complexity involved in calculating the amphibole structural formula and to experimental uncertainties. The model undoubtedly calls for further improvement. The principal difficulty consists in the absence of necessary information on the real melt components and their interrelationships. Accounting for the maximum of amphibole stability of pressure and temperature in the $P-T$ coordinates is also required.

\section{ACKNOWLEDGEMENTS}

The author is sincerely grateful to A.A. Ariskin, G.S. Barmina, R.R. Al'meev, and G.S. Nikolaev (GEOKHI RAN) for help given, for the loan of the INFOREX system, and for discussion of the results.

This work was supported by the Russian Foundation for Basic Research, project no. 05-05-65300. 


\section{REFERENCES}

1. Ariskin, A.A., Meshalkin, S.S., Al'meev, R.R., et al., The Information Search System INFOREX: Analysis and Processing of Experimental Data on Phase Equilibria of Igneous Rocks, Petrologiya, 1997, vol. 5, no. 1, pp. 32-41.

2. Kadik, A.A., Maksimov, A.P., and Ivanov, B.V., Fiziko-

khimicheskie usloviya kristallizatsii i genezis andezitov (na primere Klyuchevskoi gruppy vulkanov) (Physicochemical Conditions of Crystallization and the Origin of Andesites: The Klyuchevskoi Group of Volcanoes), Moscow: Nauka, 1986.

3. Maksimov, A.P., The Influence of Water on the Melting Curves of Minerals: the Olivine-Melt Equilibrium, Geokhimiya, 2003, no. 10, pp. 1036-1047.

4. Allen, J.C. and Boettcher, A.L., Amphiboles in Andesite and Basalts: II. Stability as a Function $P-T-f_{\mathrm{H}_{2} \mathrm{O}}-f_{\mathrm{O}_{2}}$ Amer. Mineral., 1978, vol. 63, no. 11-12, pp. 10741087.

5. Allen, J.C. and Boettcher, A.L., The Stability of Amphibole in Andesite and Basalt at High Pressures, Amer. Mineral., 1983, vol. 68, no. 3-4, pp. 307-314.

6. Allen, J.C., Boettcher, A.L., and Marland, G., Amphiboles in Andesite and Basalts: I. Stability as a Function of $P-T-f_{\mathrm{O}_{2}}$, Amer. Mineral., 1975, vol. 60, no. 11-12, pp. $1069-1085$.

7. Beard, J.S. and Lofgren, G.E., Dehydration Melting and Water-Saturated Melting of Basaltic and Andesitic Greenstones and Amphibolites at 1,3, and 6-9 kbar, $J$. Petrology, 1991, vol. 32, Part 2, pp. 365-401.

8. Burnham, C.W., Development of the Burnham Model for Prediction of the $\mathrm{H}_{2} \mathrm{O}$ Solubility in Magmas, Rev. Mineralogy, 1994, vol. 30, pp. 123-129.

9. Burnham, C.W. and Davis, N.F., The Role of $\mathrm{H}_{2} \mathrm{O}$ in Silicate Melts: II. Thermodynamic and Phase Relations in the System $\mathrm{NaAlSi}_{3} \mathrm{O}_{8}-\mathrm{H}_{2} \mathrm{O}$ to 10 kilobars, $700^{\circ}$ to $1100^{\circ}$ C, Amer. J. Sci., 1974, vol. 274, pp. 902-940.

10. Dale, J., Holland, T.J.B.and Powell, R., HornblendeGarnet-Plagioclase Thermobarometry: A Natural Assemblage Calibration of the Thermodynamics of Hornblende, Contributions to Mineralogy and Petrology, 2000, vol. 140, pp. 353-362.

11. Eggler, D.H., Amphibole Stability in $\mathrm{H}_{2} \mathrm{O}$-Undersaturated Calc-Alkaline Melts, Earth Planet. Sci. Lett., 1972, vol. 15 , no. 1, pp. 28-34.

12. Ghiorso, M.S., On the Stability Relations of Hydrous Minerals in Water-Undersaturated Magmas, Amer. Mineral., 1999, vol. 84, pp. 1505-1511.

13. Grove, T.L., Donnelly-Nolan, J.M., and Housh, T., Magmatic Processes that Generated the Rhyolite of Glass Mountain, Medicine Lake Volcano, N. California, Contribs Mineral. Petrol., 1997, vol. 127, pp. 205-223.

14. Helz, R.T., Phase Relations and Compositions of Amphiboles Produced in Studies of the Melting Behavior of Rocks, Reviews in Mineralogy, 1982, vol. 9B, pp. 279-347.

\section{JOURNAL OF VOLCANOLOGY AND SEISMOLOGY}

Vol. 3
15. Helz, R.T., Phase Relations of Basalts in Their Melting Ranges at $P_{\mathrm{H}_{2} \mathrm{O}}=5 \mathrm{~kb}$ as a Function of Oxygen Fugacity. Part I. Mafic Phases, J. Petrol., 1973, vol. 14, Part 2, pp. 249-302.

16. Helz, R.T., Phase Relations of Basalts in Their Melting Ranges at $P_{\mathrm{H}_{2} \mathrm{O}}=5 \mathrm{~kb}$ as a Function of Oxygen Fugacity. Part II. Melt Compositions, J. Petrol., 1976, vol. 17, Part 2, pp. 139-193.

17. Holland, T. and Blundy, J., Non-Ideal Interactions in Calcic Amphiboles and Their Bearing on AmphibolePlagioclase Thermometry, Contribs Mineral. Petrol., 1994, vol. 116, no. 4, pp. 433-447.

18. Holloway, J.R., The System Pargasite- $-\mathrm{H}_{2} \mathrm{O}-\mathrm{CO}_{2}$ : A Model for Melting of a Hydrous Mineral with a Mixed-Volatile Fluid-I. Experimental Results to 8 kbar, Geochim. Cosmochim. Acta, 1973, vol. 37, pp. 651-666.

19. Holloway, J.R. and Burnham, C.W., Melting Relations of Basalt with Equilibrium Water Pressure Less than Total Pressure, J. Petrol., 1972, vol. 13, Part 1, pp. 1-29.

20. Johnson, M.C., Rutherford, M.J., and Hess, P.C., Chassigny Petrogenesis: Melt Compositions, Intensive Parameters, and Water Contents of Martian Magmas, Geochim. Cosmochim. Acta, 1991, vol. 55, no. 1, pp. 349-366.

21. Maximov, A.P., Influence of water on the Mineral-Melt Equilibria: Effect of Dilution, Experiment in Geosciences, 1996, vol. 5, no. 2, pp. 14-15.

22. Maximov, A.P., The Water Influence on the Temperature of the Amphibole Stability in the Melts, Experiment in Geosciences, 2000, vol. 9, no. 1, pp. 41-42.

23. Powell, R., Thermodynamics of Coexisting Cummingtonite-Hornblende Pairs, Contrib. Mineral. Petrol., 1975, vol. 51, no. 1, pp. 29-37.

24. Rutherford, M.J., The May 18, 1980, Eruption of Mount St. Helens: 1. Melt Composition and Experimental Phase Equilibria, J. Geophys. Res., 1985, vol. 90, no. B4, pp. 2929-2947.

25. Rutherford, M.J. and Devine, J.D., The May 18, 1980, Eruption of Mount St. Helens: 3. Stability and Chemistry of Amphibole in the Magma Chamber, J. Geophys. Res., 1988, vol. 93, pp. 949-959.

26. Sato, H., Nakada, S., Fujii, T., et al., Groundmass Pargasite in the 1991-1995 Dacite of Unzen Volcano: Phase Stability Experiments and Volcanological Implications, J. Volcanol. Geotherm. Res., 1999, vol. 89, pp. 197-212.

27. Scaillet, B. and Evans, B.W., The 15 June 1991 Eruption of Mount Pinatubo. I. Phase Equilibria and Pre-Eruption $P-T-f_{\mathrm{H}_{2} \mathrm{O}}-f_{\mathrm{O}_{2}}$ Conditions of the Dacite Magma, $J$. Petrology, 1999, vol. 40, no. 3, pp. 381-411.

28. Sisson, T.W. and Grove, T.L., Experimental Investigations of the Role of $\mathrm{H}_{2} \mathrm{O}$ in Calc-Alkaline Differentiation and Subduction Zone Magmatism, Contribs. Mineral. Petrol., 1993, vol. 113, no. 2, pp. 143-166. 